\title{
Identification of highly brominated analogues of Q1 in marine mammals
}

Emma L. Teuten, Byron E. Pedler, Alexandra N. Hangsterfer and Christopher M. Reddy

Department of Marine Chemistry and Geochemistry, Woods Hole Oceanographic Institution, 360 Woods Hole Rd, Woods Hole, MA 02543, USA

E-mail addresses: ELT eteuten@whoi.edu,BEP bpedler@whoi.edu,AH ahangsterfer@whoi.edu, CMR creddy@whoi.edu

Capsule:

Three compounds bioaccumulated in marine mammals were identified as $\mathrm{C}_{9} \mathrm{H}_{3} \mathrm{~N}_{2} \mathrm{Br}_{6} \mathrm{Cl}, \mathrm{C}_{9} \mathrm{H}_{3} \mathrm{~N}_{2} \mathrm{Br}_{7}$ and $\mathrm{C}_{9} \mathrm{H}_{4} \mathrm{~N}_{2} \mathrm{Br}_{5} \mathrm{Cl}$ and are proposed to be 1'-methyl-1,2'bipyrrole natural products.

Keywords: bioaccumulation, halogenated organic compound, high resolution mass spectrometry, halogenated bipyrrole.

* Corresponding author phone: +1 (508) 289-2641; fax: +1 (508) 457-2146; email: eteuten@whoi.edu. 


\begin{abstract}
Three novel halogenated organic compounds (HOCs) have been identified in the blubber of marine mammals from coastal New England with the molecular formulae $\mathrm{C}_{9} \mathrm{H}_{3} \mathrm{~N}_{2} \mathrm{Br}_{6} \mathrm{Cl}, \mathrm{C}_{9} \mathrm{H}_{3} \mathrm{~N}_{2} \mathrm{Br}_{7}$, and $\mathrm{C}_{9} \mathrm{H}_{4} \mathrm{~N}_{2} \mathrm{Br}_{5} \mathrm{Cl}$. They were identified using high and low resolution electron ionization (EI) and electron capture negative ionization (ECNI) gas chromatography mass spectrometry (GCMS) and appear to be highly brominated analogues of Q1, a heptachlorinated HOC that has been suspected to be naturally-produced. These new compounds were found in Atlantic white sided dolphin (Lagenorhynchus acutus), bottlenose dolphin (Tursiops truncatus), common dolphin (Delphinus delphis), Risso’s dolphin (Grampus griseus), harbor porpoise (Phocoena phocoena), beluga whale (Delphinapterus leucas), fin whale (Balaenoptera physalus), grey seal (Halichoerus grypus), harp seal (Phoca groenlandica) and a potential food source (Loligo pealei) with concentrations as high as $2.7 \mu \mathrm{g} / \mathrm{g}$ (lipid weight). The regiospecificity of $\mathrm{C}_{9} \mathrm{H}_{3} \mathrm{~N}_{2} \mathrm{Br}_{6} \mathrm{Cl}$ is suggestive of a biogenic origin. Debromination of $\mathrm{C}_{9} \mathrm{H}_{3} \mathrm{~N}_{2} \mathrm{Br}_{6} \mathrm{Cl}$ may be significant in the formation of $\mathrm{C}_{9} \mathrm{H}_{4} \mathrm{~N}_{2} \mathrm{Br}_{5} \mathrm{Cl}$.
\end{abstract}

\title{
1. Introduction
}

Over the past decade, a number of previously unreported compounds have been observed to bioaccumulate in numerous organisms. These include several halogenated bipyrroles (Tittlemier et al., 1999; Vetter et al., 1999, 2000) and a selection of hydroxylated and methoxylated polybrominated diphenyl ethers (Asplund et al., 1999; Haglund et al., 1997; Malmvärn et al., 2005), none of 
which are reported to be manufactured industrially. The bioaccumulated halogenated bipyrroles contain one of two bipyrrolic backbones. A heptachlorinated 1'-methyl-1,2'-bipyrrole referred to as Q1 has been reported by Vetter et al. (1999, Wu et al., 2002) and a family of structurally similar mixed halogenated 1,1'-dimethyl-2,2'-bipyrroles (DMBPs) have been identified by Tittlemier et al. (1999) (Fig. 1). These compounds have been detected in a range of marine trophic levels, including fish, seabird eggs, and marine mammals, as well as human breast milk (Tittlemier et al., 2002a; Vetter et al., 2000). In some animals their levels are comparable to industrial HOCs, including polychlorinated biphenyls (PCBs) (Tittlemier et al., 2002b; Vetter et al., 2001); however, relative concentrations are not correlated in individual animals (Tittlemier et al. 2002b). Although both types of halogenated bipyrroles are globally distributed, Q1 is more prevalent in the Southern Hemisphere (Vetter et al., 2000) and the DMBPs are more abundant in the northern Pacific Ocean (Tittlemier et al., 2002b). This suggests that the compounds are produced in specific geographical locations and subsequently transported throughout the World oceans. The toxicity of these compounds to the organisms in which they accumulate has not been well established. However in bioactivity studies, both the DMBP congeners and Q1 were shown to bind with the aryl hydrocarbon receptor and induce cytochrome P450 activity (Tittlemier et al., 2003; Vetter et al., 2004).

It has been assumed that the observed bioaccumulated halogenated bipyrroles are natural products, as no industrial sources are known. In support of their natural origin, one bioaccumulated DMBP has been shown to be at least in 
part biogenic from analysis of its natural abundance radiocarbon content (Reddy et al., 2004). However, very few marine natural products have been identified with such a high degree of halogenation. An extensive review of halogenated marine natural products reported in the literature (made using the Marinlit database and summarized in Table 1) suggests that highly halogenated compounds are rare, with only $3 \%$ containing 6 or more halogens. Of the 1,385 known marine HOCs containing two or more halogens, only $16 \%$ are fully chlorinated. The unusual nature of Q1, with regard to the scarcity of such highly chlorinated natural products has been noted previously (Vetter et al., 1999).

While surveying for HOCs in marine mammals that had stranded on the coast of New England, we recently observed a selection of abundant unidentified halogenated compounds (UHCs) in several dolphin species. Analysis by gas chromatography high resolution mass spectrometry (GC-HRMS) revealed that three of these compounds are $\mathrm{C}_{9} \mathrm{H}_{3} \mathrm{~N}_{2} \mathrm{Br}_{6} \mathrm{Cl}, \mathrm{C}_{9} \mathrm{H}_{3} \mathrm{~N}_{2} \mathrm{Br}_{7}$, and $\mathrm{C}_{9} \mathrm{H}_{4} \mathrm{~N}_{2} \mathrm{Br}{ }_{5} \mathrm{Cl}$. Mass spectrometry and other observations support the tentative identification of these compounds as 1'-methyl-1,2'-bipyrroles (MBPs) (Fig. 1), analogues of the heptachlorinated Q1. Here we discuss our determination of these compounds and their possible biogenic origin. Our observation of a family of structurally similar compounds, containing a more highly brominated MBP skeleton than Q1, is not unreasonable given the high proportion of halogenated marine natural products containing bromine.

\section{Materials and Methods}




\subsection{Large scale extraction of UHCs}

To determine the elemental composition of the UHCs, we used the blubber of a common dolphin (Delphinus delphis). This animal was provided by the Cape Cod Stranding Network, who found it fatally stranded in Westpoint, MA. The blubber was homogenized in a blender with 1:1 solution of hexane:dichloromethane (DCM), filtered, and dried over anhydrous sodium sulfate. The resulting lipids $(50 \mathrm{~g})$ were split into two portions and charged onto a glass column packed with Bio-beads SX-8 (BioRad Laboratories), and eluted with a 2:3 solution of hexane:DCM. The HOCs were collected in the 155 to $400 \mathrm{~mL}$ fraction of the eluant. The procedure was repeated until all the lipids were removed. The HOC extract was then separated on a column packed with silica gel $(0.8 \mathrm{~g})$ and aluminum oxide $(0.5 \mathrm{~g})$, eluting with hexane. PCBs were eluted in the first $5 \mathrm{~mL}$. The second $5 \mathrm{~mL}$ fraction contained the UHCs and other HOCs. To determine the identity of the UHCs, the latter fraction was analyzed by several techniques.

To investigate the dietary contribution of UHCs to marine mammals, a potential food source was investigated. Squid (Loligo pealei) was provided by the Marine Resources Center at the Marine Biological Laboratory, who collected the animals from Vineyard Sound, Massachusetts. Four whole animals were homogenized with a Pro 250 handheld homogenizer (Pro Scientific Inc.), and the homogenate $(275 \mathrm{~g})$ was freeze dried. The dry homogenate was extracted into 9:1 hexane:methanol. The extract was washed with distilled water, dried over 
anhydrous sodium sulfate, and the solvent evaporated yielding $7.12 \mathrm{~g}$ of lipids. The HOCs were isolated as described previously.

\subsection{Identification of the UHCs}

To identify the UHCs, low resolution gas chromatography mass spectrometry (GCMS) experiments were conducted on an Agilent 6890N series GC system connected to a 5973 network mass selective detector (70 eV ionization energy), using a J \& W Scientific DB-XLB column $(60 \mathrm{~m} \times 0.25 \mathrm{~mm}$ i.d., 0.25 $\mu \mathrm{m}$ film thickness). A temperature gradient program was used, with an initial oven temperature of $50{ }^{\circ} \mathrm{C}$ for $1 \mathrm{~min}$, increased at $30{ }^{\circ} \mathrm{C} / \mathrm{min}$ to $120^{\circ} \mathrm{C}$, then by $8{ }^{\circ} \mathrm{C} / \mathrm{min}$ to $320^{\circ} \mathrm{C}$, which was held for $30 \mathrm{~min}$. The temperatures of the inlet, source, and transfer line were set at 250,230 , and $325^{\circ} \mathrm{C}$, respectively. The samples were injected in splitless mode, and helium was used as the carrier gas with a flow rate of $1.1 \mathrm{~mL} / \mathrm{min}$. For the electron capture negative ionization (ECNI) GCMS experiments, methane was employed as a reagent gas and the temperatures of the source and transfer line were decreased to 70 and $250{ }^{\circ} \mathrm{C}$, respectively. Analysis of the blubber samples were conducted in the full scan mode $(50-750$ amu). The squid extract was analyzed using single ion monitoring (SIM), scanning for the ions 575 and 577 for both UHC-1 and UHC-2 as well as the ions 697 and 699 for UHC-3.

To identify the molecular formulae of the UHCs, accurate masses for their molecular ion and fragment ions were determined by GC-HRMS. The GC-HRMS experiments were performed on a JEOL MSroute JMS-600H double focusing high 
resolution magnetic sector mass spectrometer coupled with an Agilent 6890N network gas chromatograph. Compounds were separated using a Varian VF-5ms column $(25 \mathrm{~m} \times 0.25 \mathrm{~mm}$ i.d., $0.25 \mu \mathrm{m}$ film thickness $)$. Perfluorokerosene was used as a calibration standard. Instrument resolution was set to 3000 at $10 \%$ peak height. Duplicate measurements were consistently within $5 \mathrm{ppm}$.

\subsection{Quantitation of the UHCs}

To provide an initial inventory and distribution of the UHCs, a variety of marine mammal samples were analyzed (Table 2). Atlantic white sided dolphin (Lagenorhynchus acutus), Risso's dolphin (Grampus griseus), grey seal (Halichoerus grypus), beluga whale (Delphinapterus leucas), and harbor porpoise (Phocoena phocoena) blubber samples were obtained from the Cape Cod Stranding Network and were all found stranded on the Massachusetts coast between April 2004 and July 2005. Bottlenose dolphin (Tursiops truncatus), fin whale (Balaenoptera physalus), and harp seal (Phoca groenlandica) samples, provided by Mystic Aquarium, were found stranded in Connecticut between March and June of 2004. Blubber samples were homogenized, and the lipids collected by filtration.

An aliquot of extracted lipid (2 g) was spiked with hexachloro 1,1'dimethyl-2,2'-bipyrrole (DMBP-Cl $)(1.8 \mu \mathrm{mol})$. We had the $\mathrm{DMBP}_{6} \mathrm{Cl}_{6}$ custom synthesized because it is not found in environmental samples (Gribble et al., 1999) and is structurally similar to our compounds of interest. The lipids were removed as described previously. The sample was reduced in volume to $200 \mu \mathrm{L}$ and spiked with 6-fluoro-2,2',4,4'-tetrabromo diphenyl ether (6'-F-BDE-47) (1.0 
$\mu$ mol, Chiron). The concentrations of $\mathrm{MBP}-\mathrm{Br}_{6} \mathrm{Cl}, \mathrm{MBP}-\mathrm{Br}_{7}$, and $\mathrm{DMBP}-\mathrm{Br}_{4} \mathrm{Cl}_{2}$ were estimated relative to $\mathrm{DMBP}-\mathrm{Cl}_{6}$. Each sample was injected into an HP 5890 Series II GC with a flame ionization detector (GC-FID) and separated on a CPSil 5CB column $(60 \mathrm{~m} \times 0.25 \mathrm{~mm}$ i.d., $0.25 \mu \mathrm{m}$ film thickness $)$. Comparable relative response factors by FID have been observed for compounds with a similar number of carbon atoms (Yieru et al., 1990) and a high degree of halogenation (Erickson, 1997); hence the standard used should adequately represent the MBPs, on a molar basis. $\mathrm{DMBP}-\mathrm{Br}_{4} \mathrm{Cl}_{2}$ was identified by comparison of $\mathrm{GC}$ retention times and mass spectra to that of an authentic standard. When replicate analyses were conducted, the difference in the concentrations measured was $<7 \%$. Recovery of the internal standard was $\geq 74 \%$. As a method blank, pure canola oil was extracted and analyzed by GC-FID, in which no HOCs were detected.

To test the extraction efficiency, canola oil ( 2 g) was spiked with 2,2',4,4',5,5'-hexachloro biphenyl (CB-153) (5.0 $\mu \mathrm{mol}$, Ultra Scientific), 2,2',4,4'tetrabromo diphenyl ether (BDE-47) $\left(2.5 \mu \mathrm{mol}\right.$, Ultra Scientific) and $\mathrm{DMBP}^{-\mathrm{Cl}_{6}}$ (4.5 $\mu \mathrm{mol})$. The lipids were removed as described above and 6'-F-BDE-47 (2.5 $\mu$ mol) added as a recovery standard. Recoveries for PCB-153, BDE-47 and DMBP-Cl$_{6}$, determined by GC-FID, were 92,86 , and $91 \%$, respectively. All standards were of $\geq 99 \%$ purity.

\subsection{Investigation of the stability of the UHCs}

To test the stability of the UHCs, preliminary experiments were performed. UHC extract from $D$. delphis, containing $\sim 8 \mu \mathrm{g} \mathrm{MBP}-\mathrm{Br}_{6} \mathrm{Cl}$, was added to each 
of eight quartz tubes. The solvent was evaporated. Sea water $(1 \mathrm{~mL})$ collected from Vineyard Sound, Massachusetts (salinity $=32 \%$ (Weber et al., 2002)) was added to six of the tubes. Distilled water $(1 \mathrm{~mL})$ was added to the remaining two tubes, which served as controls. The tubes were frozen in liquid nitrogen, the headspace evacuated, and the tubes sealed closed. Three tubes containing sea water and one control were placed in an oven at $70{ }^{\circ} \mathrm{C}$ in the dark for 32 days. Three tubes more tubes and one control were placed under a Philips natural sunlight fluorescent tube (negligible emission below $350 \mathrm{~nm}$ ) for 30 days. To analyze the samples, DCM $(1 \mathrm{~mL})$ was added to each tube. DMBP-Cl $_{6}(1.8 \mu \mathrm{g})$ was added as a standard. The contents of the tube were transferred into a separatory funnel, distilled water $(2 \mathrm{~mL})$ added, and the UHCs extracted into $2 \times$ $10 \mathrm{~mL}$ DCM. The extract was analyzed by GCMS.

\section{Results and Discussion}

\subsection{Analysis of HOCs}

The HOC extract isolated from $D$. delphis was analyzed by low resolution GCMS using both EI and ECNI as ionization sources. In addition to observing many industrially-synthesized HOCs, several peaks were seen whose spectra did not correspond to any compounds reported in the literature. To better investigate these UHCs, the bulk $\mathrm{HOC}$ extract was separated using silica gel $/ \mathrm{Al}_{2} \mathrm{O}_{3}$ column chromatography. The UHCs eluted in a slightly more polar fraction than the PCBs and most of the 1,1-dichloro-2,2-bis(4-chlorophenyl)-ethene (p,p'-DDE). A GCMSEI total ion chromatogram for the UHC fraction is shown in Fig. 2. This fraction 
contained all of the extracted UHCs, and some of the bioaccumulated industrial HOCs from the previous fraction. The most abundant industrial HOCs in the UHC enriched extract were cis and trans nonachlor, 1,1-dichloro-2,2-bis(4chlorophenyl)-ethane ( $p, p^{\prime}$-DDD) and $p, p^{\prime}$-DDE.

\subsection{Tentative identification of UHC-1}

The most abundant UHC observed by GCMS-EI (UHC-1, Fig. 2) had an isotopic cluster resembling a compound containing one chlorine and six bromine atoms at $648 \mathrm{Da}$ (Fig. 3A). This was confirmed as the molecular ion by GCMSECNI (Fig. 3B) for which no ions heavier than those in this ion cluster were seen. The exact molecular formula was determined by GC-HRMS. The measured accurate mass of the parent ion was compared to masses calculated for species with the following isotopic restrictions: $\mathrm{H}(0-20), \mathrm{C}(7-14), \mathrm{N}(0-3), \mathrm{Cl}(0-5), \mathrm{Br}$ (0-7), O (0-4), S (0-2). The elemental composition with the smallest difference between the measured and calculated masses, also containing an appropriate number of bromine and chlorine atoms to explain the observed isotopic pattern, was deemed the most probable molecular formula. A search of possible molecular formulae within $\pm 5 \mathrm{ppm}$ of the measured molecular ion revealed 13 possibilities. Only one of these chemical formulae contained the correct proportion of halogens to account for the isotopic pattern of the molecular ion cluster. Accordingly, UHC-1 was identified as $\mathrm{C}_{9} \mathrm{H}_{3} \mathrm{~N}_{2} \mathrm{Br}{ }_{6} \mathrm{Cl}$. Table 3 lists the measured and calculated masses of a selection of ions for this compound. In all cases, the fragment ion was identified as the species with the smallest difference between the measured 
and calculated masses, also containing an appropriate degree of halogenation to account for the isotopic pattern of the ion cluster.

A literature search revealed no compounds with the elemental composition $\mathrm{C}_{9} \mathrm{H}_{3} \mathrm{~N}_{2} \mathrm{Br}_{6} \mathrm{Cl}$. Analysis of the compound by high and low resolution GCMS yielded some information about the chemical structure. The predominant fragment ions resulted from loss of $\mathrm{Br}^{\circ}, \mathrm{Cl}^{\circ}$ and $\mathrm{CH}_{3}{ }^{\circ}$. Observation of a methyl group accounts for all of the hydrogens in this compound. The low ratio of carbon to other atoms suggests a high degree of saturation. Following these observations, we propose the most reasonable structure for $\mathrm{C}_{9} \mathrm{H}_{3} \mathrm{~N}_{2} \mathrm{Br}_{6} \mathrm{Cl}$ is chloro hexabromo 1'methyl 1,2'-bipyrrole (Fig. 1, $\mathrm{MBP}-\mathrm{Br}_{6} \mathrm{Cl}$ ). There are five possible isomers of $\mathrm{MBP}-\mathrm{Br}_{6} \mathrm{Cl}$. However when the UHC extract was analyzed with two capillary columns of different polarity (DB-XLB and DB-5MS), only one peak was observed for this compound using GCMS. This suggests that only one isomer is present. The absence of other isomers suggests a highly regioselective or regiospecific synthesis of these compounds. This degree of selectivity is suggestive of natural production. There currently insufficient information to identify the location of the chlorine atom. In the mixed halogenated DMBPs reported by Tittlemier et al. (2002a), chlorination of the carbon adjacent to the $\mathrm{N}^{-\mathrm{CH}_{3}}$ group is exclusively observed; this pattern may also be observed for MBPs. This position is known to be the most reactive to electrophiles in monopyrroles (Jones, 1990), and the regiospecificity may reflect a degree of electrophilic character in the chlorination mechanism of halogenated bipyrroles. The most effective method for identifying the specific isomer of $\mathrm{MBP}-\mathrm{Br}_{6} \mathrm{Cl}$ would be to isolate a sufficient 
quantity to obtain nuclear magnetic resonance (NMR) spectra and conduct an Xray crystallographic analysis. This will require isolation of a considerable amount of material. The identity of the compound may be verified by synthesis of an authentic standard and comparison of mass spectra and relative GC retention times (Teuten et al., 2005a).

\subsection{Determination of UHC-2 and UHC-3}

Similar procedures identified UHC-2 and UHC-3. UHC-2, an apparently monochlorinated pentabrominated compound with a molecular ion at $570 \mathrm{Da}$, was determined to be $\mathrm{C}_{9} \mathrm{H}_{4} \mathrm{~N}_{2} \mathrm{Br}{ }_{5} \mathrm{Cl}$. UHC-3, which has an isotopic pattern characteristic of a heptabrominated compound and molecular ion at $691 \mathrm{Da}$, was identified as $\mathrm{C}_{9} \mathrm{H}_{3} \mathrm{~N}_{2} \mathrm{Br}_{7}$. Calculated and measured masses for the molecular ions and prominent fragment ions for UHC-2 and UHC-3 are listed in Table 3. A literature search indicated no known compounds with these molecular formulae. As with UHC-1, the MS-EI spectra of these compounds show predominant loss of halogens (Fig. 4). Further similarities between the mass spectra of these three compounds suggest they have similar molecular structures. We propose that the structures of $\mathrm{C}_{9} \mathrm{H}_{3} \mathrm{~N}_{2} \mathrm{Br}_{7}$ and $\mathrm{C}_{9} \mathrm{H}_{4} \mathrm{~N}_{2} \mathrm{Br} 5 \mathrm{Cl}$ are $\mathrm{MBP}^{-\mathrm{Br}_{7}}$ and $\mathrm{MBP}-\mathrm{HBr}{ }_{5} \mathrm{Cl}$, respectively (Fig. 1).

All three UHCs show a fairly abundant doubly charged $[\mathrm{M}-2 \mathrm{Br}]^{2+}$ ion. These peaks show the same halogen isotopic pattern as the singly charged ions, but the peaks are only separated by 1 Da. For UHC- 1 and UHC-3, this peak is of a comparable intensity to that of the molecular ion. Abundant $[\mathrm{M}-2 \mathrm{Br}]^{2+}$ ions 
were also observed for DMBPs (Tittlemier et al., 1999). However, the compounds identified in this report are clearly not DMBPs, as the molecular formulae determined from the accurate masses contain an insufficient number of hydrogens to furnish two methyl groups. Additionally, GC-HRMS experiments identified the ions $\mathrm{C}_{4} \mathrm{BrCl}^{+}$and $\mathrm{C}_{4} \mathrm{Br}_{2}{ }^{+}$for UHC-1 and UHC-3, respectively. These are interesting fragments arising from either the non-methylated pyrrole ring or from a rearrangement of the methyl group into the N-methyl pyrrole ring (Jones, 1990) with subsequent fragmentation. This fragmentation does not appear to have been reported for monopyrroles. The 1'-methyl 1,2'-bipyrrole system is uncommon and its typical mass spectrometry has not been discussed in the literature. A similar ion is seen for UHC-2 at $84 \mathrm{Da}$, which is consistent with $\mathrm{C}_{4} \mathrm{HCl}^{+}$including the isotopic pattern. An accurate mass was not determined for this ion, so this identity cannot be definitively assigned. These proposed structures contain the same bipyrrole skeleton as $\mathrm{Q} 1$, which also accumulates in the blubber of marine mammals. When examining the GCMS-EI spectrum for Q1 published in the literature (Vetter et al., 1999) an ion was seen at $118 \mathrm{Da}$, with an isotopic distribution suggestive of two chlorines. It is possible that this peak corresponds to $\mathrm{C}_{4} \mathrm{Cl}_{2}{ }^{+}$, supporting a structural similarity between the compounds identified here and Q1.

\subsection{Quantitation of the UHCs}

The concentrations of $\mathrm{MBP}-\mathrm{Br}_{6} \mathrm{Cl}$ and $\mathrm{MBP}-\mathrm{Br}_{7}$ in a selection of marine mammals found stranded on the coasts of Massachusetts and Connecticut were 
estimated using GC-FID and are listed in Table 2. For reference, the concentration of one of the most abundant PCBs in the samples, CB-153, is also reported. In all cases the concentration of CB-153 is higher than that of the MBPs. No correlation between the MBP concentrations and CB-153 were seen. Although it appears that the MBPs may be more abundant in dolphin than other species of marine mammals, it must be noted that the sample selection includes adult dolphins but only juvenile animals of other species. Recorded trends for HOCs in marine mammals show higher amounts in mature than in immature animals (Borgå et al., 2004). Thus, higher MBP concentrations in dolphins may be a consequence of increased accumulation with age.

To investigate the mode of transfer of the MBPs to marine mammals, a potential dietary component was examined. Squid are known to be a preferred food source of common and white-sided dolphins in the New England area (Weisbrod et al., 2000). Analysis of the squid HOC extract by GCMS-ECNI using SIM showed the presence of all three MBPs discussed herein. This indicates that these compounds bioaccumulate in dolphins, and likely other marine mammals, as a result of dietary exposure. Stable nitrogen isotope analysis of whole tissues has revealed that structurally similar DMBPs are present at a range of trophic levels (Tittlemier et al., 2002a) and further analysis may indicate the same phenomenon for MBPs.

A screening for other halogenated bipyrroles known to accumulate in marine mammal blubber revealed $\mathrm{DMBP}-\mathrm{Br}_{4} \mathrm{Cl}_{2}$ in some animals (Table 2). Several dolphin samples also contained a small peak whose spectra appeared to 
match that of Q1, although this identity could not be confirmed due to lack of an authentic standard.

To illustrate the potential for the MBPs to bioaccumulate, estimated vapor pressures and octanol-water partition coefficients $\left(\mathrm{K}_{\mathrm{ow}}\right)$ were compared with those of industrial HOCs. Using U.S. Environmental Protection Agency EPI (Estimation Programs Interface) Suite software, the vapor pressures and $\mathrm{K}_{\mathrm{ow}}$ were estimated at $0.1 \times 10^{-6}$ to $2 \times 10^{-6} \mathrm{~Pa}$ and $>10^{7}$, respectively. It is worth noting that when a similar approach was used for the DMBPs, for which the vapor pressure and $\mathrm{K}_{\mathrm{ow}}$ have been experimentally determined (Tittlemier et al. 2004a), this software overestimated $\log \mathrm{K}_{\mathrm{ow}}$ by an order of magnitude and under-estimated the vapor pressure by approximately two orders of magnitude. The difference between the estimated and experimentally determined values for the DMBPs suggests similar errors may be observed for the MBPs. Nevertheless, the estimated values indicate a tendency for these compounds to bioaccumulate and are similar to values for PCBs with $\geq 5$ chlorines.

\subsection{Origin and distribution}

Although these compounds have not been reported previously, it is possible they have gone undetected in samples from other locations. They may have been missed either because they were not recognized, or because they were unstable under the conditions used to remove the lipids. Early attempts in this study to isolate the UHCs by saponification or acid degradation of the lipids resulted in loss of the MBPs. Interestingly, Q1 did not show significant reaction with 
concentrated sulfuric acid (Vetter et al., 1999). The higher reactivity of the brominated MBPs compared to Q1 likely arises because bromine is a better leaving group than chlorine.

It has been suggested previously that bioaccumulated bipyrroles are produced naturally (Reddy et al., 2004; Wu et al., 2002). The presence of radiocarbon in one bioaccumulated DMBP implies, at least in part, a biogenic origin (Reddy et al., 2004). Additionally, a structurally similar hexabrominated 2,2'-bipyrrole is a known marine bacterial metabolite (Andersen et al., 1974). However, there are no known sources of MBPs, either natural or industrial. While it is possible that these MBPs are unreported byproducts of industrial processes, their structural similarity to biogenic compounds suggests that they are produced naturally by an unidentified marine organism. Work is underway to isolate sufficient amounts of these compounds for analysis of their natural abundance radiocarbon content, which will allow us to distinguish between a natural and an industrial source (Reddy et al., 2002; Teuten et al., 2005b). Stable isotope analysis of the individual compounds will likely also provide insight into their source. Analysis of $\delta^{13} \mathrm{C}$ and $\delta^{15} \mathrm{~N}$ may identify the carbon source and the trophic level of the organism that originally synthesized the compounds (McClelland and Montoya, 2002).

A large number of halogenated natural products have been identified (Gribble, 2003), including some that resemble persistent, anthropogenic contaminants (Carté and Faulkner 1981; Utkina et al., 2001, 2002). As discussed in the introduction, very few highly halogenated marine natural products are 
known, and of these only one of these contains a bipyrrole moiety (Andersen et al., 1974). However, it must be noted that this record is far from complete, as newly discovered halogenated natural products are reported on a regular basis. As illustrated in Table 1, a small proportion (16\%) of the known natural HOCs containing two or more halogens are fully chlorinated. This may seem unexpected, as chloride is $\sim 300$ times more abundant in seawater than bromide (Pilson, 1998). The preference for bromination is likely due to the lower oxidation potential of bromide (Price et al., 1988), resulting in its more facile incorporation into organic compounds by halogenase enzymes. In light of this, the heptachlorinated nature of Q1 is unusual. The existence of a family of structurally similar compounds, containing a more highly brominated MBP skeleton than Q1 seems reasonable given the high proportion of halogenated natural products containing bromine. Interestingly, there are a range of other similar compounds containing different proportions of chlorine and bromine that were not present in our samples, including $\mathrm{MBP}-\mathrm{Br}_{5} \mathrm{Cl}_{2}, \mathrm{MBP}-\mathrm{Br}_{4} \mathrm{Cl}_{3}, \mathrm{MBP}-\mathrm{Br}_{3} \mathrm{Cl}_{4}, \mathrm{MBP}-\mathrm{Br}_{2} \mathrm{Cl}_{5}$ and $\mathrm{MBP}-\mathrm{BrCl}_{6}$. It is possible that these compounds will also eventually be found in biological samples.

It is plausible that more highly chlorinated MBPs form by halide exchange reactions, in which the equilibrium is shifted toward an increase in chlorination, due to the higher concentration of chloride in seawater relative to bromide. Marine halogen exchange reactions occur primarily by light-activated radical reactions or nucleophilic exchange (Ballschmiter, 2003). To probe the possibility of halide exchange reactions occurring by these two mechanisms on the MBPs 
extracted from $D$. delphis, solvent-free UHC extract was mixed with seawater and exposed to either heat or light at natural sunlight wavelengths. No halide exchange was observed for a sample stored at $70{ }^{\circ} \mathrm{C}$ in the dark for 32 days, or after 30 days of continuous exposure to simulated sunlight. These results do not support formation of more highly chlorinated MBPs by simple halogen exchange reactions.

Biological transformations of the MBPs are also possible. For example, debromination of $\mathrm{MBP}-\mathrm{Br}{ }_{6} \mathrm{Cl}$ could generate $\mathrm{MBP}-\mathrm{HBr}{ }_{5} \mathrm{Cl}$. Debromination of other HOCs, including polybrominated diphenyl ethers (PBDEs) and hexabromobenzene, has been observed in carp (Stapleton et al., 2004) and rats (Yamaguchi et al., 1988), respectively. Various microbial dehalogenation reactions are known (Janssen et al., 2001). As discussed above, only one isomer of $\mathrm{MBP}^{-\mathrm{Br}}{ }_{6} \mathrm{Cl}$ was detected in the samples examined. Loss of one bromine atom from this compound could result in the formation of four to six possible isomers of $\mathrm{MBP}-\mathrm{HBr}_{5} \mathrm{Cl}$. After close inspection of eight samples listed in Table 2 using GCMS-ECNI, we found three additional compounds that we have tentatively identified as isomers of UHC2 on the basis of their mass spectra. Assuming a comparable response factor for all four of these compounds, UHC-2 was at least 10 times more abundant than the other isomers in all the samples. Nevertheless, this suggests formation of $\mathrm{MBP}-\mathrm{HBr}_{5} \mathrm{Cl}$ by a regioselective, but not regiospecific, debromination of MBP$\mathrm{Br}_{6} \mathrm{Cl}$. If indeed $\mathrm{MBP}-\mathrm{Br}_{6} \mathrm{Cl}$ is a natural product, it would have been in the environment long before the manufacture and release of industrial HOCs beginning in the 1920s (Stringer and Johnston, 2001). A number of ubiquitous industrial 
HOCs are known to undergo microbial dehalogenation reactions (Smidt and de Vos, 2002). It is possible that the environmental presence of MBPs may have helped organisms to develop the pathways by which they dehalogenate structurally similar industrial HOCs, such as PCBs.

Limited knowledge surrounding the bioactivity of halogenated bipyrroles suggests that the compounds we have reported herein may induce a biological response (Tittlemier et al., 2003; Vetter et al., 2004). The potential human health implications are unknown. Halogenated DMBPs have been observed in a variety of fish and seafood available for commercial retail throughout Canada, indicating exposure of humans to these compounds (Tittlemier, 2004b). Human exposure to halogenated bipyrroles is also apparent through detection of Q1 in the breast milk of women from the Faroe Islands (Vetter et al., 2000). These observations suggest that more detailed work should be conducted on the exposure of humans to halogenated bipyrroles and the implications of such exposure. Last, if truly naturally produced, these compounds have likely been present in the environment for a much longer time period than industrially-synthesized HOCs. Therefore, these compounds may be excellent subjects to study the long-term fate of HOCs with similar physical properties, such as PCBs.

\section{Conclusions}

In summary, three novel bioaccumulated compounds have been identified in the blubber of marine mammals from New England. These compounds have been identified as $\mathrm{C}_{9} \mathrm{H}_{3} \mathrm{~N}_{2} \mathrm{Br}_{6} \mathrm{Cl}, \mathrm{C}_{9} \mathrm{H}_{3} \mathrm{~N}_{2} \mathrm{Br}_{7}$ and $\mathrm{C}_{9} \mathrm{H}_{4} \mathrm{~N}_{2} \mathrm{Br}{ }_{5} \mathrm{Cl}$ by GC-HRMS. The 
evidence supports these three compounds having a 1'-methyl 1,2'-bipyrrole skeleton, identical to that of the heptachlorinated MBP, Q1. This suggests the existence of a family of MBPs with different halogenation patterns, akin to the DMBPs reported by Tittlemier et al. (1999). A tendency for the MBPs to accumulate in various species of marine mammals, particularly dolphins, has been observed. Our identification of $\mathrm{MBP}-\mathrm{HBr}_{5} \mathrm{Cl}$ represents the first report of a bioaccumulated bipyrrole whose rings are not fully halogenated.

\section{Acknowledgements}

We thank the Cape Cod Stranding Network and Mystic Aquarium for providing blubber samples. We are grateful to Andrea Bogomolni and Eric Montie for helpful discussions and to Sean Sylva and Bob Nelson for help transporting samples. We also thank Alex Sessions for support and helpful discussions. GCHRMS experiments were conducted by Mona Shahgholi and Lilach Somberg at California Institute of Technology. This work was supported by the National Science Foundation (OCE-0221181), the Woods Hole Oceanographic Institution

(WHOI) Ocean Life Institute, the Postdoctoral Scholar Program at WHOI (with funding from The Camille and Henry Dreyfus Foundation, Inc. and The J. Seward Johnson Fund) (ELT) and The Island Foundation, Inc (BEP). This is WHOI contribution \#

\section{References}


Andersen F.W., Wolfe M.S., Faulkner D.J., 1974. Autotoxic antibiotic production by a marine Chromobacterium. Mar. Biol. 27, 281-285.

Asplund L., Athanasiadou M., Sjödin A., Bergman A., Börjeson H., 1999. Organohalogen substances in muscle, egg and blood from healthy Baltic salmon (Salmo salar) and salmon that produced offspring with the M74 syndrome. Ambio 27, 67-76.

Ballschmiter K., 2003. Pattern and sources of naturally produced organohalogens in the marine environment: biogenic formation of organohalogens. Chemosphere $52,313-324$.

Borgå K., Fisk A.T., Hoekstra P.F., Muir D.C.G., 2004. Biological and chemical importance in the bioaccumulation and trophic transfer of persistent organochlorine contaimants in arctic marine food webs. Environ. Toxicol. Chem. $23,2367-2385$.

Carté B., Faulkner D.J., 1981. Brominated diphenyl ethers from Dysidea herbacea, Dysidea chlorea and Phyllospongia foliascens. Tetrahedron 37, 2335-2339.

Erickson M.D., 1997. Analytical chemistry of PCBs, CRC Press, Boca Raton.

Gribble G.W., Blank D.H., Jasinski J.P., 1999. Synthesis and identification of two halogenated bipyrroles present in seabird eggs. Chem. Commun. 2195-2196.

Gribble G.W., 2003. The diversity of naturally produced organohalogens. Chemosphere 52, 289-297.

Haglund P.S., Zook D.R., Buser H., Hu J., 1997. Identification of polybrominated diphenyl ethers and methoxy-polybrominated diphenyl ethers in Baltic biota. Environ. Sci. Technol. 31, 3281-3287. 
Janssen D.B., Oppentocht J.E., Poelarends G.J., 2001. Microbial dehalogenation. Current Opinion in Biotechnology 12, 254-258.

Jones R.A., 1990. Pyrroles. Part 1. The synthesis and the physical and chemical aspects of the pyrrole ring, Wiley, New York.

Malmvärn A., Marsh G., Kautsky L., Athanasiadou M., Bergman Å., Asplund L., 2005. Hydroxylated and methoxylated brominated diphenyl ethers in the red algae Ceramium tenuicorne and blue mussels from the Baltic Sea. Environ. Sci. Technol. 39, 2990-2997.

McClelland J.W., Montoya J.P., 2002. Trophic relationships and the nitrogen isotopic composition of amino acids in plankton. Ecology 83, 2173-2180.

Pauly D., Trites A.W., Capuli E., Christensen V., 1998. Diet composition and trophic levels of marine mammals. J. Mar. Sci. 55, 467-481.

Pilson M.E.Q., 1998. Introduction to the chemistry of the sea, Prentice Hall, Upper Saddle River NJ.

Price D., Iddon B., Wakefield B.J., 1988. Bromine Compounds: Chemistry and Applications, Elsevier, Amsterdam.

Reddy C.M., Xu L., Eglinton T.I., Boon J.P., Faulkner D.J., 2002. Radiocarbon content of synthetic and natural semi-volatile halogenated organic compounds. Environ. Pollut. 120, 163-168.

Reddy C.M., Xu L., O'Neil G.W., Nelson R.K., Eglinton T.I., Faulkner D.J., Norstrom R., Ross P.S., Tittlemier S.A., 2004. Radiocarbon evidence for a naturally produced, bioaccumulating halogenated organic compound. Environ. Sci. Technol. 38, 1992-1997. 
Smidt H., de Vos W.M., 2004. Anaerobic microbial dehalogenation. Annu. Rev. Microbiol. 58, 43-73.

Stapleton H.M., Letcher R.J., Baker J.E., 2004. Debromination of polybrominated diphenyl ether congeners $\mathrm{BDE} 99$ and $\mathrm{BDE} 183$ in the intestinal tract of the common carp (Cyprinus carpio). Environ. Sci. Technol. 38, 1054-1061.

Stringer R., Johnston P., 2001. Chlorine and the environment: an overview of the chlorine industry, Kluwer Academic Publishers, Dordrecht.

Teuten E.L., Johnson C.G., Mandalakis M., Asplund L., Gustafsson Ö., Unger M., Marsh G., Reddy C.M., 2005a. Spectral characterization of two bioaccumulated methoxylated polybrominated diphenyl ethers. Chemosphere in press.

Teuten E.L., Xu L., Reddy C.M., 2005b. Two abundant bioaccumulated halogenated compounds are natural products. Science 307, 917-920.

Tittlemier S.A., Simon M., Jarman W.M., Elliott J.E., Norstrom R., 1999. Identification of a novel $\mathrm{C}_{10} \mathrm{H}_{6} \mathrm{~N}_{2} \mathrm{Br}_{4} \mathrm{Cl}_{2}$ heterocyclic compound in seabird eggs. A bioaccumulating marine natural product? Environ. Sci. Technol. 33, 26-33.

Tittlemier S.A., Fisk A.T., Hobson K.A., Norstrom R.J., 2002a. Examination of the bioaccumulation of halogenated dimethyl bipyrroles in an Arctic marine food web using stable nitrogen isotope analysis. Environ. Pollut. 116, 85-93.

Tittlemier S., Borrell A., Duffe J., Duignan P.J., Fair P., Hall A., Hoekstra P., Kovacs K.M., Krahn M.M., Lebeuf M., Lydersen C., Muir D., O'Hara T., Olsson M., Pranschke J., Ross P., Siebert U., Stern G., Tanabe S., Norstrom R., 2002b. Global distribution of halogenated dimethyl bipyrroles in marine mammal blubber. Arch. Environ. Contam. Toxicol. 43, 244-255. 
Tittlemier S.A., Kennedy S.W., Hahn M.E., Reddy C.M., Norstrom R.J., 2003. Naturally produced halogenated dimethyl bipyrroles bind to the aryl hydrocarbon receptor and induce cytochrome $\mathrm{P} 4501 \mathrm{~A}$ and porphorin accumulation in chicken embryo hepatocytes. Environ. Toxicol. Chem. 22, 1622-1631.

Tittlemier S.A., Braekevelt E., Halldorson T., Reddy C.M., Norstrom, R.J., 2004a. Vapour pressures, aqueous solubilities, Henry's Law constants, and octanol/water partition coefficients of a series of mixed halogenated dimethyl pyrroles. Chemosphere 57, 1373-1381.

Tittlemier S.A., 2004b. Dietary exposure to a group of naturally produced organohalogens (halogenated dimethyl bipyrroles) via consumption of fish and seafood. J. Agr. Food Chem. 52, 2010-2015.

Utkina N.K., Denisenko V.A., Scholokova O.V., Virovaya M.V., Gerasimenko A.V., Popov D.Y., Krasokhin V.K., Popov A.M., 2001. Spongiadioxins A and B, two new polybrominated dibenzo-p-dioxins from an Australian marine sponge Dysidea dendyi. J. Nat. Prod. 64, 151-153.

Utkina N.K., Denisenko V.A., Virovaya M.V., Scholokova O.V., Prokof'eva, N.G., 2002. Two new minor polybrominated dibenzo-p-dioxins from the marine sponge Dysidea dendyi. J. Nat. Prod. 65, 1213-1215.

Vetter W., Alder L., Palavinskas R., 1999. Mass spectrometric characterization of Q1, a $\mathrm{C}_{9} \mathrm{H}_{3} \mathrm{Cl}_{7} \mathrm{~N}_{2}$ contaminant in environmental samples. Rapid Commun. Mass Spectrom. 13, 2118-2124. 
Vetter W., Alder L., Kallenborn R., Schlabach M., 2000. Determination of Q1, an unknown organochlorine contaminant, in human milk, Antarctic air, and further environmental samples. Environ. Pollut. 110, 401-409.

Vetter W., Scholz E., Gaus C., Müller J.F., Haynes D., 2001. Anthropogenic and natural organohalogen compounds in the blubber of dolphins and dugongs (Dugong dugon) from Northeastern Australia. Arch. Environ. Contam. Toxicol. 41, 221-231.

Vetter W., Hahn M.E., Tomy G., Ruppe S., Vatter S., Chahbane N., Lenoir D., Schramm K-W., Scherer G., 2004. Biological activity and physicochemical parameters of marine halogenated natural products $2,3,3^{\prime}, 4,4^{\prime}, 5,5^{\prime}$-heptachloro-1methyl-1,2'-bipyrrole and 2,4,6-tribromoanisole. Arch. Environ. Contam. Toxicol. $48,1-9$.

Weber C.F., Barron S., Marino R., Howarth R.W., Tomasky G., Davidson E.A., 2002. Nutrient limitation in Vineyard Sound and Oyster Pond, Falmouth, Massachusetts. Biol. Bull. 203, 261-263.

Weisbrod A.V., Shea D., Moore M.J., Stegeman J.J., 2000. Bioaccumulation patterns of polychlorinated biphenyls and chlorinated pesticides in Northwest Atlantic pilot whales. Environ. Toxicol. Chem. 19, 667-677.

Wu J., Vetter W., Gribble G.W., Schneekloth J.S., Blank D.H., Görls H., 2002. Structure and synthesis of the natural heptachloro-1'-methyl-1,2'-bipyrrole (Q1). Angew. Chem. Int. Ed. 41, 1740-1743. 
Yamaguchi Y., Kawano M., Tatsukawa R., 1988. Tissue distribution and excretion of hexabromobenzene and its debrominated metabolites in the rat. Arch. Environ. Contam. Toxicol. 17, 807-812.

Yieru H., Quingu O., Weile Y., 1990. Characteristics of flame ionization detection for the quantitative analysis of complex organic mixtures. Anal. Chem. 62, 2063-2064. 


\section{Figures Captions}

Fig. 1. Halogenated bipyrroles bioaccumulated in the marine food web. Q1 was identified by Vetter et al. (1999) and the DMBPs by Tittlemier et al. (1999).

Fig. 2. GCMS-EI chromatogram of the UHC fraction of blubber extract from $D$. delphis. The prevalent, unlabelled peaks are HOCs whose identification is in progress. The PCBs and most of the $p, p^{\prime}$-DDE have been removed from this sample.

Fig. 3. GCMS spectra of UHC-1 (MBP-Br$\left.{ }_{6} \mathrm{Cl}\right)$, using (A) EI and (B) ECNI.

Fig. 4. GCMS-EI spectrum of (A) UHC-2 (MBP-HBr $\left.{ }_{5} \mathrm{Cl}\right)$ and (B) UHC-3 (MBP$\left.\mathrm{Br}_{7}\right)$. 


\section{Tables}

\section{Table 1.}

Distribution of halogens in known marine halogenated natural products. A preference for polyhalogenated compounds to contain exclusively bromine or a combination of different halogens is observed. The data in this table was compiled using the MarinLit database (February 2005 update).

\begin{tabular}{lcccccccccc}
\hline & \multicolumn{7}{c}{ \# halogens } \\
\cline { 2 - 11 } & 1 & 2 & 3 & 4 & 5 & 6 & 7 & 8 & 11 \\
\hline \# fully chlorinated natural products & 544 & 82 & 51 & 30 & 13 & 45 & 0 & 0 & 2 \\
\# fully brominated natural products & 601 & 406 & 107 & 112 & 21 & 23 & 1 & 3 & 0 \\
\# fully iodinated natural products & 36 & 11 & 3 & 2 & 0 & 0 & 0 & 0 & 0 \\
\# mixed halogenated natural products & - & 188 & 155 & 81 & 37 & 12 & 0 & 0 & 0 \\
\hline
\end{tabular}


Table 2.

Estimated concentrations of HOCs in a selection of marine mammals stranded in New England, listed in order of decreasing trophic status (Pauly et al., 1998).

\begin{tabular}{|c|c|c|c|c|c|c|c|c|}
\hline \multirow[t]{2}{*}{ animal } & \multirow[t]{2}{*}{ Details $^{a}$} & \multicolumn{6}{|c|}{ Concentration $(\mu \mathrm{g} / \mathrm{g} \text { lipid })^{\mathrm{b}}$} & \multirow[t]{2}{*}{ Accession no. } \\
\hline & & $\mathrm{MBP}-\mathrm{Br}_{6} \mathrm{Cl}$ & $\mathrm{MBP}-\mathrm{Br}_{7}$ & $\mathrm{MBP}-\mathrm{HBr}_{5} \mathrm{Cl}$ & DMBP- $\mathrm{Br}_{6} \mathrm{Cl}_{2}$ & Q1 & CB-153 & \\
\hline Risso's dolphin (G. griseus) & $\mathrm{m}, \mathrm{j}$. & 1.7 & 0.4 & + & + & + & 2.7 & CCSN05-188Gg \\
\hline Risso's dolphin ( $G$. griseus) & $\mathrm{m}, \mathrm{a}$ & 1.0 & 0.1 & + & + & + & 1.5 & CCSN05-192Gg \\
\hline Common dolphin (D. delphis) & $\mathrm{m}, \mathrm{a}$ & 2.7 & 1.1 & + & 0.5 & + & 7.8 & CCSN04-177Dd \\
\hline Common dolphin (D. delphis) & $\mathrm{f}, \mathrm{j}$ & 1.2 & 1.6 & + & - & - & 2.3 & CCSN04-219Dd \\
\hline Common dolphin (D. delphis) & $\mathrm{m}, \mathrm{j}$ & 0.4 & 0.5 & + & + & - & 0.7 & CCSN04-218Dd \\
\hline Bottlenose dolphin (T. truncatus) & $\mathrm{f}, \mathrm{a}$ & 2.1 & 1.1 & + & - & - & 15.8 & SxTt0410 \\
\hline Atlantic white sided dolphin (L. acutus) & $\mathrm{m}, \mathrm{a}$ & 1.9 & 0.7 & + & 0.2 & + & 8.4 & CCSN04-116La \\
\hline Atlantic white sided dolphin (L. acutus) & $\mathrm{f}, \mathrm{a}$ & 2.5 & 2.7 & + & - & - & 3.9 & CCSN05-040La \\
\hline Harbor porpoise (P. phocoena) & $\mathrm{m}, \mathrm{j}$ & 0.2 & 0.2 & + & - & - & 0.8 & CCSN04-030Pp \\
\hline Gray seal (H. grypus) & $\mathrm{m}, \mathrm{j}$ & 0.3 & 0.03 & + & - & - & 5.0 & CCSN04-186Hg \\
\hline Beluga whale (D. leucas) & $\mathrm{m}, \mathrm{j}$ & 0.1 & 0.01 & + & + & - & 0.9 & 04513-D1 \\
\hline Harp seal ( $P$. groenlandica) & $\mathrm{m}, \mathrm{j}$ & 0.04 & 0.005 & + & - & - & 0.1 & SyPg04180314 \\
\hline Fin whale (B. physalus) & $\mathrm{m}, \mathrm{j}$ & 0.2 & 0.1 & + & - & - & 1.1 & SyBp0448 \\
\hline Squid (L. pealei) & & 0.002 & 0.007 & + & - & - & 0.1 & \\
\hline
\end{tabular}

${ }^{\mathrm{a}} \mathrm{m}=$ male, $\mathrm{f}=$ female, $\mathrm{a}=$ adult, $\mathrm{j}=$ juvenile, n.a. $=$ not available. ${ }^{\mathrm{b}}-=$ not detected, $+=$ detected by GCMS, but not quantified (concentrations were either below the GC-FID detection limit or co-eluted in the GC-FID analysis). 
Table 3 .

Measured and calculated masses for the molecular ions and fragment ions of UHC-1, UHC-2, and UHC-3 detected in D. delphis blubber, determined by GCHRMS.

\begin{tabular}{|c|c|c|c|c|c|}
\hline Compound & Ion & $\begin{array}{c}\text { Fragment } \\
\text { lost }\end{array}$ & $\begin{array}{l}\text { Measured mass } \\
\text { (Da) }\end{array}$ & $\begin{array}{c}\text { Calculated mass } \\
\text { (Da) }\end{array}$ & $\begin{array}{c}\text { Difference } \\
(\mathrm{ppm})\end{array}$ \\
\hline \multirow[t]{9}{*}{ UHC-1 } & $\mathrm{C}_{9} \mathrm{H}_{3} \mathrm{~N}_{2} \mathrm{Br}_{6} \mathrm{Cl}^{+}$ & - & 647.5084 & 647.5085 & 0.2 \\
\hline & $\mathrm{C}_{9} \mathrm{H}_{3} \mathrm{~N}_{2} \mathrm{Br}_{6}^{+}$ & $\mathrm{Cl}^{\circ}$ & 612.5381 & 612.5396 & -2.5 \\
\hline & $\mathrm{C}_{9} \mathrm{H}_{3} \mathrm{~N}_{2} \mathrm{Br}_{5} \mathrm{Cl}^{+}$ & $\mathrm{Br}^{\circ}$ & 568.5895 & 568.5902 & -1.2 \\
\hline & $\mathrm{C}_{9} \mathrm{H}_{3} \mathrm{~N}_{2} \mathrm{Br}_{4} \mathrm{Cl}^{+}$ & $2 \mathrm{Br}$ & 489.6738 & 489.6718 & 4.1 \\
\hline & $\mathrm{C}_{9} \mathrm{H}_{3} \mathrm{~N}_{2} \mathrm{Br}_{3} \mathrm{Cl}^{+}$ & $3 \mathrm{Br}^{\circ}$ & 410.7537 & 410.7535 & 0.6 \\
\hline & $\mathrm{C}_{8} \mathrm{~N}_{2} \mathrm{Br}_{2}{ }^{81} \mathrm{BrCl}^{+}$ & $3 \mathrm{Br}^{\circ}$ & 397.7301 & 397.7280 & 5.3 \\
\hline & & $\mathrm{CH}_{3}{ }^{\circ}$ & & & \\
\hline & $\mathrm{C}_{9} \mathrm{H}_{3} \mathrm{~N}_{2} \mathrm{Br}^{81} \mathrm{BrCl}^{+}$ & $4 \mathrm{Br}^{\circ}$ & 333.8336 & 333.8331 & 1.5 \\
\hline & $\mathrm{C}_{4} \mathrm{BrCl}^{+}$ & & 161.8870 & 161.8872 & -1.1 \\
\hline \multirow[t]{5}{*}{ UHC-2 } & $\mathrm{C}_{9} \mathrm{H}_{4} \mathrm{~N}_{2} \mathrm{Br}_{4}{ }^{81} \mathrm{BrCl}^{+}$ & - & 571.5953 & 571.5959 & -1.0 \\
\hline & $\mathrm{C}_{9} \mathrm{H}_{4} \mathrm{~N}_{2} \mathrm{Br}_{4}{ }^{81} \mathrm{Br}^{+}$ & $\mathrm{Cl}^{\circ}$ & 536.6246 & 536.6270 & -4.5 \\
\hline & $\mathrm{C}_{9} \mathrm{H}_{4} \mathrm{~N}_{2} \mathrm{Br}_{4} \mathrm{Cl}^{+}$ & $\mathrm{Br}^{\circ}$ & 490.6785 & 490.6796 & -2.2 \\
\hline & $\mathrm{C}_{9} \mathrm{H}_{4} \mathrm{~N}_{2} \mathrm{Br}_{3} \mathrm{Cl}^{+}$ & $2 \mathrm{Br}$ & 411.7620 & 411.7613 & 1.7 \\
\hline & $\mathrm{C}_{9} \mathrm{H}_{4} \mathrm{~N}_{2} \mathrm{Br}_{2} \mathrm{Cl}^{+}$ & $3 \mathrm{Br}$ & 322.8421 & 332.8430 & -2.7 \\
\hline \multirow[t]{8}{*}{ UHC-3 } & $\mathrm{C}_{9} \mathrm{H}_{4} \mathrm{~N}_{2} \mathrm{Br}_{4}{ }^{81} \mathrm{Br}_{3}^{+}$ & - & 697.4524 & 697.4518 & 0.8 \\
\hline & $\mathrm{C}_{9} \mathrm{H}_{4} \mathrm{~N}_{2} \mathrm{Br}_{6}^{+}$ & $\mathrm{Br}^{\circ}$ & 612.5392 & 612.5396 & 0.7 \\
\hline & $\mathrm{C}_{9} \mathrm{H}_{4} \mathrm{~N}_{2} \mathrm{Br}_{4}{ }^{81} \mathrm{Br}^{+}$ & $2 \mathrm{Br}$ & 535.6180 & 535.6192 & -2.3 \\
\hline & $\mathrm{C}_{9} \mathrm{H}_{4} \mathrm{~N}_{2} \mathrm{Br}_{4}^{+}$ & $3 \mathrm{Br}^{\circ}$ & 454.7015 & 454.7029 & -3.1 \\
\hline & $\mathrm{C}_{8} \mathrm{~N}_{2} \mathrm{Br}_{3}{ }^{81} \mathrm{Br}^{+}$ & $3 \mathrm{Br}$ & 441.6767 & 441.6774 & -1.7 \\
\hline & & $\mathrm{CH}_{3}{ }^{\circ}$ & & & \\
\hline & $\mathrm{C}_{9} \mathrm{H}_{4} \mathrm{~N}_{2} \mathrm{Br}_{2}{ }^{81} \mathrm{Br}^{+}$ & $4 \mathrm{Br}$ & 377.7837 & 377.7826 & 2.9 \\
\hline & $\mathrm{C}_{4} \mathrm{Br}^{81} \mathrm{Br}^{+}$ & & 207.8372 & 207.8346 & 2.6 \\
\hline
\end{tabular}

